\section{Correspondence}

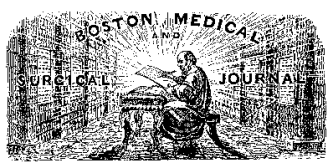

\section{Bone Marrow Metastases in Breast Cancer}

To the Editor: In their study of the histochemical detection of metastases from breast cancer to bone marrow, Braun et al. (Feb. 24 issue $)^{1}$ found that multivariate analysis identified the presence of cytokeratin-positive cells in the bone marrow as an independent predictor of survival. What do the authors think about the use of flow cytometry after cytokeratin staining? Their results clearly demonstrate that the presence of cytokeratin-positive cells in the bone marrow of patients with breast carcinoma is associated with shorter survival. However, because cytokeratin-positive cells were detected in control patients with nonmalignant disease and stage I tumors had fewer than 5 cytokeratin-positive cells per $2 \times 10^{6}$ bone marrow cells, the authors should also clarify the threshold of positivity needed to avoid false positive results. Braun et al. found a median of 3 cytokeratin-positive cells per $2 \times 10^{6}$ bone marrow cells, but the exclusion of patients with fewer than 3 cytokeratin-positive cells per $2 \times 10^{6}$ bone marrow cells would not be enough, because the confidence interval for each stage is not mentioned.

Salvador J. Diaz-Cano, M.D., Ph.D. St. Bartholomew's and the Royal London School of Medicine and Dentistry London El 1BB, United Kingdom

1. Braun S, Pantel K, Müller P, et al. Cytokeratin-positive cells in the bone marrow and survival of patients with stage I, II, or III breast cancer. N Engl J Med 2000;342:525-33.
To the Editor: Thanks to improved screening procedures, the average diameter of most newly diagnosed breast tumors is $1.5 \mathrm{~cm}$, and tumors larger than $5 \mathrm{~cm}$ are rare..$^{1-3}$ Hence, the tumor-size variable ( $\leqslant 5 \mathrm{~cm}$ vs. $>5 \mathrm{~cm}$ ) chosen by Braun et al. for multivariate analysis does not reflect the clinical situation. Analysis of the preliminary results of our own study of 905 patients with a median follow-up of 53 months (range, 7 to 112 ) revealed that lymph-node status and tumor size are independent prognostic features of breast cancer. We used anticytokeratin antibodies to detect isolated epithelial cells in bone marrow. When we dichotomized tumor size as $\leqslant 2 \mathrm{~cm}$ or $>2 \mathrm{~cm}$ in multivariate analysis, bone marrow status was not an independent prognostic factor in breast cancer. This result reflects the strongest multivariate model according to scoring and goodness of fit. However, when we dichotomized tumor size as $\leqslant 5 \mathrm{~cm}$ or $>5 \mathrm{~cm}$, we confirmed the independent prognostic effect of the bone marrow status reported by Braun et al. Notably, in the study by Braun et al., this large size had no effect on overall survival, although it was associated with the development of distant metastases, an event that is evidently correlated with a poor prognosis.

ILONA FunKe, M.D. Winfried SCHRAUT, M.D., M.P.H.

Klinikum Grosshadern 81377 Munich, Germany

1. Braun S, Pantel K, Müller P, et al. Cytokeratin-positive cells in the bone marrow and survival of patients with stage I, II, or III breast cancer. N Engl J Med 2000;342:525-33.

2. Smith BL. Approaches to breast-cancer staging. N Engl J Med 2000; 342:580-1.

3. Cady B, Stone MD, Schuler JG, Thakur R, Wanner MA, Lavin PT. The new era in breast cancer: invasion, size, and nodal involvement dramatically decreasing as a result of mammographic screening. Arch Surg 1996;131: 301-8.

To the Editor: It is possible that the cytokeratin-positive cells identified by Braun et al. represent cells in the circulation $^{1}$ that were aspirated together with the bone marrow and

\title{
INSTRUCTIONS FOR LETTERS TO THE EDITOR
}

Letters to the Editor are considered for publication (subject to editing and abridgment) provided they do not contain material that has been submitted or published elsewhere. Please note the following: • Your letter must be typewritten and triple-spaced. $\bullet$ Its text, not including references, must not exceed 400 words (please include a word count). •It must have no more than five references and one figure or table -It should not be signed by more than three authors. - Letters referring to a recent Journal article must be received within four weeks of its publication. $\bullet$ Please include your full address, telephone number, and fax number (if you have one). $\bullet$ You may send us your letter by post, fax, or electronic mail.

Our address: Letters to the Editor • New England Journal of Medicine 110 Shattuck St. • Boston, MA 02115

Our fax numbers: 617-739-9864 and 617-734-4457

Our e-mail address: letters@nejm.org

We cannot acknowledge receipt of your letter, but we will notify you when we have made a decision about publication. We are unable to provide prepublication proofs. Please enclose a stamped, self-addressed envelope if you want unpublished material returned to you. Financial associations or other possible conflicts of interest must be disclosed. Submission of a letter constitutes permission for the Massachusetts Medical Society, its licensees, and its assignees to use it in the Journal's various editions (print, data base, and optical disk) and in anthologies, revisions, and any other form or medium. 
that were not derived from bone marrow. This distinction is important, since circulating cells are one rung below cells that have transmigrated through the target tissue's endothelial, basement-membrane, and connective-tissue barriers.

We therefore believe that the designation "micrometastasis" is too restrictive. It is obvious that finding such cells does not change the stage of cancer to stage IV, because many such cases of cancer can be cured, a goal that is currently not achievable with stage IV cancer. If, indeed, this protocol does become part of clinical practice, then a less-alarming designation should be used, possibly microdissemination, or MD. Adding the designation MD to the stage without changing the stage of the cancer may reduce the patient's anxiety as well as the risk of overtreatment by physicians.

Eli Pikarsky, M.D. TAmar Peretz, M.D.

Hadassah Medical Center 91120 Jerusalem, Israel

1. Mori M, Mimori $\mathrm{K}$, Ueo $\mathrm{H}$, et al. Clinical significance of molecular detection of carcinoma cells in lymph nodes and peripheral blood by reverse transcription-polymerase chain reaction in patients with gastrointestinal or breast carcinomas. J Clin Oncol 1998;16:128-32.

The authors reply:

To the Editor: Although defining the threshold of positivity would help to avert a few false positive results (in our series the rate was 1 percent), it would also increase the rate of false negative findings, because 90 of 199 patients with positive cells ( 45 percent) had only 1 or 2 cytokeratinpositive cells per bone marrow sample. The statement that patients with stage I breast cancer "had fewer than $5 \mathrm{cy}$ tokeratin-positive cells" is wrong, since we wrote that "patients with stage I cancer had a mean of 5 tumor cells per $2 \times 10^{6}$ bone marrow cells." Because of the low numbers of immunostained cells, flow cytometry is not an adequate approach, unless an efficient and reproducible tumor-cellenrichment procedure can be used.

We recalculated our multivariate statistics, with tumor size dichotomized as $\leqslant 2 \mathrm{~cm}$ or $>2 \mathrm{~cm}$, and found that the bone marrow status remained an independent prognostic factor, with hazard ratios of 5.80 (95 percent confidence interval, 3.74 to $9.00 ; \mathrm{P}<0.001)$ for survival free of distant disease and 3.76 (95 percent confidence interval, 2.25 to $6.27 ; \mathrm{P}<0.001$ ) for overall survival. Tumor size became an independent prognostic indicator of the risk of death from cancer, with the remaining values (as shown in Table 2 of our article) essentially unchanged. The discrepancy between our findings and those of Funke and Schraut may reflect the fact that they used the monospecific anticytokeratin-18 antibody CK2, which is less sensitive ${ }^{1}$ than the broad-spectrum monoclonal antibody A45-B/B3 that we used in our study.

With current aspiration techniques, the possibility that circulating tumor cells are obtained with bone marrow tumor cells cannot be excluded. Nevertheless, the frequency of tumor cells in the circulation of patients with stage I, II, or III breast cancer is considerably lower than that of disseminated tumor cells in bone marrow, which decreases the likelihood that a major fraction of the tumor cells identified in our study stemmed from the peripheral blood.
We agree with Drs. Pikarsky and Peretz that the term "micrometastases" may be misleading; "occult metastatic cells" or "isolated tumor cells" 2 may be better alternatives.

STEPHAN Braun, M.D.

Technische Universität München D-81675 Munich, Germany

GÜNTER SCHLIMOK, M.D.

Zentralklinikum Augsburg D-86165 Augsburg, Germany

Klaus Pantel, M.D.

Universitätsklinikum Eppendorf D-20246 Hamburg, Germany

1. Braun S, Müller M, Hepp F, Schlimok G, Riethmuller G, Pantel K. Re: Micrometastatic breast cancer cells in bone marrow at primary surgery: prognostic value in comparison with nodal status. J Natl Cancer Inst 1998 ; 90:1099-101

2. Hermanek P, Hutter RV, Sobin LH, Wittekind C. International Union Against Cancer: classification of isolated tumor cells and micrometastasis. Cancer 1999;86:2668-73.

\section{Amiodarone to Prevent Recurrence of Atrial Fibrillation}

To the Editor: Roy et al. (March 30 issue) $)^{1}$ report that amiodarone is more efficacious than sotalol or propafenone for the prevention of recurrences of atrial fibrillation. However, a significantly greater proportion of the patients assigned to sotalol or propafenone had left ventricular hypertrophy (21 percent) than of those assigned to amiodarone (13 percent) $(\mathrm{P}=0.04)$. As we already know, hypertensive heart disease is the most common antecedent to the development of atrial fibrillation. ${ }^{2}$

Some of the greater efficacy of amiodarone, as compared with the other two agents, can be explained by the difference between the two groups in the prevalence of left ventricular hypertrophy. This point can be validated by carefully looking at the post hoc analysis (Fig. 2 of the article). In patients who did not have left ventricular hypertrophy, the hazard ratio for the recurrence of atrial fibrillation was much more strongly in favor of amiodarone than was the case in the study population as a whole, since there were significantly fewer patients with left ventricular hypertrophy in the amiodarone group. Had there been more patients with left ventricular hypertrophy in the amiodarone group, the efficacy of amiodarone would have appeared to be much less.

Moreover, although only one patient in the propafenoneor-sotalol group died of arrhythmia, the current weight of evidence is sufficient to prohibit the use of class IC antiarrhythmic agents in patients with coronary artery disease. ${ }^{3}$ Eighteen percent of the patients in the propafenone-orsotalol group in this trial had coronary artery disease.

Atul Aggarwal, M.D. University of Vermont College of Medicine Burlington, VT 05401

1. Roy D, Talajic M, Dorian P, et al. Amiodarone to prevent recurrence of atrial fibrillation. N Engl J Med 2000;342:913-20.

2. Kannel WB, Abbott RD, Savage DD, McNamara PM. Epidemiologic features of chronic atrial fibrillation: the Framingham Study. N Engl J Med 1982;306:1018-22. 
3. The Cardiac Arrhythmia Suppression Trial (CAST) Investigators. Pre liminary report: effect of encainide and flecainide on mortality in a randomized trial of arrhythmia suppression after myocardial infarction. $\mathrm{N}$ Engl J Med 1989;321:406-12

To the Editor: It is interesting that at a time of increased focus on drug safety, Roy et al. have published an encouraging report on the efficacy of amiodarone for the treatment of atrial fibrillation. The authors conclude that low doses of amiodarone are relatively safe and suggest that amiodarone may be used as first-line therapy for the prevention of recurrences of atrial fibrillation. However, this study had a number of exclusion criteria, the patients were treated in the controlled setting of a clinical trial, and it was of relatively short duration. We are concerned that the relative safety of amiodarone as observed in this study may not be able to be extrapolated to patients treated in typical clinical settings.

Currently, because of life-threatening adverse effects and difficulties in management, amiodarone is approved by the Food and Drug Administration only for the treatment of documented, life-threatening recurrent ventricular arrhythmias (i.e., ventricular fibrillation or ventricular tachycardia causing hemodynamic instability) when other agents have been tried unsuccessfully. If the use of amiodarone is to be extended to other indications, then possible adverse effects and potentially serious drug interactions must be considered.

Although there are a number of clinically important drug interactions involving amiodarone, two warrant special attention. As seen in this trial, warfarin or digoxin is frequently among the medications taken by patients who are given amiodarone (approximately one third of the study patients were taking digoxin, and over half were taking anticoagulant drugs). There is an increase in the prothrombin time and the international normalized ratio when amiodarone and warfarin are prescribed concomitantly, most likely because of the inhibition of warfarin metabolism. The dose of warfarin may need to be adjusted (e.g., decreased by 33 to 50 percent) to achieve the patient's target international normalized ratio to reduce the risk of bleeding. ${ }^{1-3}$ An interaction between digoxin and amiodarone may also result in increased digoxin concentrations, possibly because of a reduction in renal and nonrenal clearance, which may result in toxic effects due to digoxin. The dose of digoxin may need to be reduced (e.g., by 50 percent) and adjusted to a therapeutic level. ${ }^{1-3}$

Elaine M. Furmaga, Pharm.D.

Department of Veterans Affairs Pharmacy Benefits Management Washington, DC 20420

Chester B. Good, M.D., M.P.H. Department of Veterans Affairs Medical Advisory Panel Washington, DC 20420

1. McEvoy GK, ed. AHFS drug information 2000. Bethesda, Md.: American Society of Health-System Pharmacists, 2000.

2. Hansten PD, Horn JR. Drug interactions analysis and management Vancouver, B.C.: Applied Therapeutics, 1998.

3. Singh BN. Amiodarone: the expanding antiarrhythmic role and how to follow a patient on chronic therapy. Clin Cardiol 1997;20:608-18.

The authors reply:

To the Editor: We thank the correspondents for their thoughtful comments. In response to Aggarwal's comments
Table 1. Cox Proportional-Hazards Model for the Recurrence of Atrial Fibrillation.*

$\begin{array}{lcc}\text { Factor } & \begin{array}{c}\text { Regression } \\ \text { Coefficient }\end{array} & \begin{array}{c}\text { Hazard Ratio } \\ \text { (95\% CI) }\end{array} \\ \text { Treatment with amiodarone } & -0.84 \pm 0.15 & 0.43(0.32-0.58) \\ \text { Presence of left ventricular hypertrophy } & -0.02 \pm 0.19 & 0.98(0.67-1.43)\end{array}$

*Plus - minus values are the regression coefficients \pm SE. Hazard ratios are for the recurrence of atrial fibrillation in the patients with the factor in question, as compared with those without the factor. CI denotes confidence interval.

about the proportions of patients with left ventricular hypertrophy in the two treatment groups, we refer to Figure 2 of the article, which shows that amiodarone was superior to propafenone or sotalol in patients without left ventricular hypertrophy (hazard ratio, 0.20 ) and in those with left ventricular hypertrophy (hazard ratio, 0.47). Despite the difference between these hazard ratios, there was no statistical evidence of an interaction between the treatment assignment and the presence or absence of left ventricular hypertrophy. In addition, a Cox model with adjustment for left ventricular hypertrophy indicates that the presence of left ventricular hypertrophy did not predict the recurrence of atrial fibrillation and that treatment assignment was strongly predictive of outcome, regardless of the presence or absence of left ventricular hypertrophy (Table 1).

The patient in the propafenone-or-sotalol group who died because of a presumed arrhythmia was receiving sotalol at the time of death. Although propafenone is a class IC agent, it was not part of the Cardiac Arrhythmia Suppression Trial, which Aggarwal cites. However, it is clear that there is an increased risk of sudden death, presumably due to the proarrhythmic effects of antiarrhythmic drugs, among patients with substantial underlying structural heart disease. Safety was an important issue in the design of our trial; we excluded patients who had had a myocardial infarction during the previous six months, those with unstable angina, and those with New York Heart Association class III or IV congestive heart failure. Furthermore, the drug doses were adjusted according to age, sex, body weight, and renal function in order to decrease the likelihood of a proarrhythmic event.

Furmaga and Good are correct: if the use of amiodarone is to be extended, possible adverse effects must be considered. Amiodarone potentiates the effect of warfarin, and because this interaction may be erratic, frequent measurement of the prothrombin time (especially during the first few weeks of administration of loading doses) is essential. Since amiodarone also increases serum digoxin concentrations, reduction of the dose of digoxin is recommended. These considerations and the well-known noncardiac side effects have limited the use of amiodarone in the past and will do so in the future. However, other large, multicenter trials ${ }^{1-3}$ have evaluated the safety of low-dose amiodarone in much greater depth than did our trial. These studies have shown that this drug can be used safely with appropriate monitoring. As we stated in the Discussion section of our article, amiodarone should be considered as first-line ther- 
apy for patients with atrial fibrillation and structural heart disease and not for all patients.

Mario Talajic, M.D. Denis Roy, M.D.

Jean Lambert, Ph.D.

Montreal Heart Institute Montreal, QC HIT 1C8, Canada

1. Connolly SJ. Evidence-based analysis of amiodarone efficacy and safety. Circulation 1999;100:2025-34.

2. Vorperian VR, Havighurst TC, Miller S, January CT. Adverse effects of low dose amiodarone: a meta-analysis. J Am Coll Cardiol 1997;30:791-8. 3. Amiodarone Trials Meta-Analysis Investigators. Effect of prophylactic amiodarone on mortality after acute myocardial infarction and in congestive heart failure: meta-analysis of individual data from 6500 patients in randomised trials. Lancet 1997;350:1417-24.

\section{Hypertension and Antihypertensive Therapy as Risk Factors for Type 2 Diabetes Mellitus}

To the Editor: Gress et al. (March 30 issue) ${ }^{1}$ report the findings of a study of the risk factors for type 2 diabetes mellitus associated with hypertension and antihypertensive therapy. The authors report that beta-blockers increase the risk of diabetes by 28 percent in patients with hypertension. I would like to point out some caveats and other issues that were not mentioned in the article. First, it must be noted that this increased risk is lower than that commonly perceived to be associated with this class of medications. As Sowers and Bakris note in their accompanying editorial, beta-blockers have proven cardiovascular benefits, and this must be weighed against the risk of diabetes. ${ }^{2}$ These cardiovascular benefits have been proved in patients with diabetes. ${ }^{3}$ Second, it is important to make a distinction between the generation of beta-blocking drugs available at the time the trial was performed and newer drugs that have additional pharmacologic properties (i.e., the blocking of alpha receptors) and that may not produce the same effect.

A specific example of this is carvedilol, which has been shown in several small trials to have neutral or slightly favorable effects on glycemic control. Jacob et al. ${ }^{4}$ conducted a three-month study involving 72 hypertensive patients who did not have diabetes in which the effects of carvedilol were compared with those of metoprolol on insulin sensitivity and found that carvedilol had neutral-to-favorable effects on glucose metabolism. Giugliano et al. found that glucose and hemoglobin $\mathrm{A}_{1 \mathrm{C}}$ levels as well as insulin sensitivity were maintained with carvedilol but worsened with atenolol. ${ }^{5}$

The authors themselves conclude that the adverse effect of the beta-blockers observed in this trial must be weighed against the proven benefits of beta-blockers. Until further studies that differentiate among the drugs within this very broad class are conducted, beta-blockers must continue to be part of the physician's armamentarium in fighting cardiovascular disease, especially in patients with diabetes.

DAVID S.H. BELL, M.B. University of Alabama School of Medicine at Birmingham Birmingham, AL 35294

1. Gress TW, Nieto FJ, Shahar E, Wofford MR, Brancati FL. Hypertension and antihypertensive therapy as risk factors for type 2 diabetes mellitus. N Engl J Med 2000;342:905-12.
2. Sowers JR, Bakris GL. Antihypertensive therapy and the risk of type 2 diabetes mellitus. N Engl J Med 2000;342:969-70.

3. Malmberg K, DIGAMI (Diabetes Mellitus, Insulin Glucose Infusion in Acute Myocardial Infarction) Study Group. Prospective randomised study of intensive insulin treatment on long term survival after acute myocardial infarction in patients with diabetes mellitus. BMJ 1997;314:1512 5 .

4. Jacob S, Rett K, Wicklmayr M, Agrawal B, Augustin HJ, Dietze GJ. Differential effect of chronic treatment with two beta-blocking agents on insulin sensitivity: the carvedilol-metoprolol study. J Hypertens 1996;14: 489-94. [Erratum, J Hypertens 1996;14:1382.]

5. Giugliano D, Acampora R, Marfella R, et al. Metabolic and cardiovascular effects of carvedilol and atenolol in non-insulin-dependent diabetes mellitus and hypertension: a randomized, controlled trial. Ann Intern Med 1997; 126:955-9.

The authors reply:

To the Editor: We agree that there is strong evidence that beta-blockers reduce the risk of cardiovascular disease in adults with or without diabetes mellitus. ${ }^{1,2}$ Such evidence must weigh heavily in decisions about whether to prescribe beta-blockers to adults at risk for type 2 diabetes, probably even more heavily than evidence from our study that betablockers appear to increase the risk of the development of type 2 diabetes. In fact, we thought that the elevation in risk that we observed would be reassuring to advocates of beta-blockers, in the light of previous estimates that were several times higher. As suggested in the Discussion section of our article, we hope that our findings prompt greater vigilance for the occurrence of diabetes in patients who use beta-blockers, without prompting abandonment of these valuable, time-tested agents. We also agree that there may be important differences among subclasses of beta-blockers with regard to the risk of diabetes, ${ }^{3}$ but the investigation of such differences was beyond the scope of our study.

Todd W. Gress, M.D., M.P.H. Frederick L. Brancati, M.D., M.H.S.

Johns Hopkins Medical Institutions Baltimore, MD 21205-2223

1. Gottlieb SS, McCarter RJ, Vogel RA. Effect of beta-blockade on mortality among high-risk and low-risk patients after myocardial infarction. N Engl J Med 1998;339:489-97.

2. Chen J, Marciniak TA, Radford MJ, Wang Y, Krumholz HM. Betablocker therapy for secondary prevention of myocardial infarction in elderly diabetic patients: results from the National Cooperative Cardiovascular Project. J Am Coll Cardiol 1999;34:1388-94.

3. Giugliano D, Acampora R, Marfella R, et al. Metabolic and cardiovascular effects of carvedilol and atenolol in non-insulin-dependent diabetes mellitus and hypertension: a randomized, controlled trial. Ann Intern Med 1997;126:955-9.

The editorialists reply:

To the Editor: Bell's comments are welcome. It should be noted, however, that no controlled trials have evaluated cardiovascular outcomes with any alpha- and beta-blocking drug, including carvedilol, in patients with hypertension in the absence of heart failure. Consider the observation in the Antihypertensive and Lipid Lowering Treatment to Prevent Heart Attack Trial ${ }^{1}$ that the alpha-blocker doxazosin, which has an excellent metabolic profile, was not as beneficial as diuretics in reducing the risk of cardiovascular events. Accordingly, the cardiovascular protective effects of beta-blockers cannot currently be extrapolated to drugs with a combination of alpha- and beta-blocking properties until appropriate 
clinical trials demonstrate that these combination agents have the same cardiovascular protective properties.

JAMEs R. SOWERS, M.D.

State University of New York Health Science Center at Brooklyn Brooklyn, NY 11203-2098

George L. BAKris, M.D.

Rush-Presbyterian-St. Luke's Medical Center Chicago, IL 60612

1. Davis BR, Cutler JA, Gordon DJ, et al. Rationale and design for the Antihypertensive and Lipid Lowering Treatment to Prevent Heart Attack Trial (ALLHAT). Am J Hypertens 1996;9:342-60.

\section{Munchausen's Syndrome Presenting as Baroreflex Failure}

To the Editor: Baroreflex failure is characterized by episodes of severe hypertension and tachycardia, ${ }^{1}$ alternating with episodes of normal or even low blood pressure and bradycardia. ${ }^{2}$ It is often caused by interruption of the baroreflex arch as a result of bilateral damage to the glossopharyngeal and vagus nerves from trauma, radiation, or surgery. Less often, the lesion is in the brain stem, ${ }^{3}$ and in some cases, the primary cause is not found.

A 68-year-old woman was referred for evaluation of baroreflex failure because of a four-year history of severe episodes of hypertension (systolic blood pressure $>200 \mathrm{~mm} \mathrm{Hg}$ for two to four days) alternating with periods of gradualonset hypotension (in which the systolic blood pressure dropped below $70 \mathrm{~mm} \mathrm{Hg}$ over a period of hours), bradycardia (requiring a pacemaker), and extreme sleepiness.

Plasma norepinephrine levels were elevated (900 pg per milliliter) during the hypertensive episodes and inappropriately low ( $54 \mathrm{pg}$ per milliliter) during the hypotensive episodes, changes consistent with the occurrence of baroreflex failure. However, there was no apparent cause, and baroreflex gain (the magnitude of proportional changes in heart rate per unit change in blood pressure) was only mildly reduced. A suppression test with $0.3 \mathrm{mg}$ of clonidine reduced the blood pressure from 158/99 to $105 / 62 \mathrm{~mm} \mathrm{Hg}$, the heart rate from 93 to 66 beats per minute, and the plasma norepinephrine level from 961 to 93 pg per milliliter, reproducing the conditions recorded during spontaneous episodes.

The alpha ${ }_{2}$-antagonist yohimbine, whose effects are the opposite of those of clonidine, reduced the severity and duration of the hypotensive episodes. Plasma samples obtained before and during a hypotensive episode revealed clonidine levels in the high therapeutic range (Fig. 1), indicating that the cause of the episodes was Munchausen's syndrome. The patient denied taking clonidine and refused psychiatric assistance, but the episodes did not recur during nine months of follow-up with strict supervision of the patient by her family and the removal of all medications from the home. The severity of her disorder is underscored by her willingness to undergo invasive diagnostic procedures and treatments (arteriography, Swan-Ganz monitoring, placement of a pacemaker, and possible brain-stemdecompression surgery). The duration of her illness (four

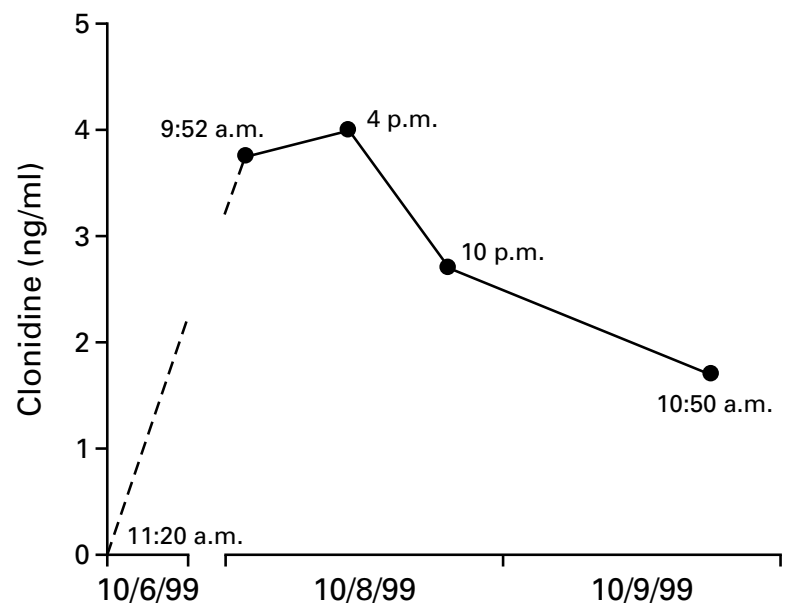

Figure 1. Plasma Levels of Clonidine before and during a "Spontaneous" Episode of Hypotension.

The therapeutic range of clonidine is 0.5 to $4.5 \mathrm{ng}$ per milliliter.

years) emphasizes the difficulties in diagnosing this disease and its lack of recognition in the medical community.

Tahir Tellioglu, M.D. John A. OATES, M.D. ItAlo Biaggioni, M.D.

Vanderbilt University Nashville, TN 37232-2195

1. Robertson D, Hollister AS, Biaggioni I, Netterville JL, Mosqueda-Garcia R, Robertson RM. The diagnosis and treatment of baroreflex failure. N Engl J Med 1993;329:1449-55.

2. Jordan J, Shannon JR, Black BK, et al. Malignant vagotonia due to selective baroreflex failure. Hypertension 1997;30:1072-7.

3. Biaggioni I, Whetsell WO, Jobe J, Nadeau JH. Baroreflex failure in a patient with central nervous system lesions involving the nucleus tractus solitarii. Hypertension 1994;23:491-5.

\section{Kaposi's Sarcoma}

To the Editor: In their review of Kaposi's sarcoma, Drs. Antman and Chang (April 6 issue $)^{1}$ thoroughly discuss the therapeutic options for advanced and aggressive Kaposi's sarcoma and conclude that "all the drugs studied so far have clinically significant systemic side effects." Treatment options for cases of less severe disease were omitted from the discussion by Antman and Chang.

Until recently, the treatment of less severe cutaneous Kaposi's sarcoma has been limited to the destructive approaches of cryotherapy with liquid nitrogen and intralesional vinblastine. Although effective in the treatment of individual cutaneous lesions of Kaposi's sarcoma, these approaches are painful and cause scarring.

An advance in treatment was the development of 1 percent alitretinoin gel. ${ }^{2-5}$ Alitretinoin (9-cis-retinoic acid) is a retinoid panagonist, since the compound binds to all six known retinoid receptors (retinoic acid receptor $\alpha, \beta$, and $\gamma$ and retinoid $\mathrm{X}$ receptor $\alpha, \beta$, and $\gamma$ ). The long-term use 
of retinoids as antiproliferative agents is well established in dermatology. One percent alitretinoin gel is the only topical agent approved by the Food and Drug Administration for AIDS-related Kaposi's sarcoma.

As investigators in clinical trials of 1 percent alitretinoin gel, we have found that this medication represents an addition to the armamentarium of safe and well-tolerated outpatient treatments for limited cutaneous Kaposi's sarcoma. It represents the only patient-approved therapy for Kaposi's sarcoma whose side effects are limited to reactions at the application sites.

Ken Washenik, M.D., Ph.D.

Lesley Clark-Loeser, M.D.

Alvin Friedman-Kien, M.D.

New York University School of Medicine New York, NY 10016

Editor's note: The Department of Dermatology at New York University School of Medicine has received funding to perform clinical trials of 1 percent alitretinoin gel, and Drs. Washenik and Friedman-Kien have served as consultants to Ligand Pharmaceuticals (the manufacturer of 1 percent alitretinoin gel), have received speakers' fees from the company, or both.

1. Antman K, Chang Y. Kaposi’s sarcoma. N Engl J Med 2000;342:102738.

2. Clark-Loeser L, Friedman-Kien A, Washenik K. Alitretinoin gel for the topical treatment of AIDS-related Kaposi's sarcoma. Today's Ther Trends 1999;17:289-302.

3. Bodsworth N, International Panretin Gel KS Study Group. Topical

9-cis-retinoic acid (Panretin) gel as treatment of cutaneous AIDS-related Kaposi's sarcoma: interim results of an international, placebo-controlled trial (ALRT 1057-503). Presented at the 12th World AIDS Conference, Geneva, June 28-July 3, 1998.

4. Krown SE. Clinical overview: issues in Kaposi's sarcoma therapeutics. In: Journal of the National Cancer Institute. Monograph 23. Bethesda, Md.: National Cancer Institute, 1998:59-63.

5. Walmsley S, Northfelt DW, Melosky B, Conant M, Friedman-Kien AE, Wagner B. Treatment of AIDS-related cutaneous Kaposi's sarcoma with topical alitretinoin (9-cis-retinoic acid) gel. J Acquir Immune Defic Syndr $1999 ; 22: 235-46$

To the Editor: In their timely review of Kaposi's sarcoma, Antman and Chang mention that commercial preparations of human chorionic gonadotropin may provide some therapeutic benefit in this disease. Clinical-grade preparations of human chorionic gonadotropin are derived from the urine of pregnant women and hence contain a mixture of biologic contaminants. These preparations are heterogeneous because of the various methods of urine conservation, extraction, and purification used. ${ }^{1}$ We have recently found that in some commercial preparations available in Belgium (Pregnyl, Organon, Oss, the Netherlands), substances extracted together with the human chorionic gonadotropin dimer stimulate the growth of Kaposi's sarcoma-derived cells. ${ }^{2}$ We therefore suggest the cautious use of preparations of human chorionic gonadotropin in clinical practice.

Thierry Simonart, M.D. Jean-Paul Van Vooren, M.D. Sylvain MEURIS, M.D. Erasme University Hospital B-1070 Brussels, Belgium
1. Nagy AM, Meuris S, Robyn C. Inventory of the molecular heterogeneity of purified human chorionic gonadotropin preparations as revealed by immunoelectrotransfer. Med Sci Res 1989;17:771-3.

2. Simonart T, Hermans P, Van Vooren JP, Meuris S. Paradoxical proKaposi's sarcoma activity of preparations of human chorionic gonadotropin. Blood 1999;94:376-7.

To the Editor: In their article, Antman and Chang underscored the role of Kaposi's sarcoma-associated herpesvirus (KSHV), also called human herpesvirus 8 (HHV-8), ${ }_{1}^{1}$ in the development of body-cavity lymphomas, Kaposi's sarcoma, and multicentric Castleman's disease. Multicentric Castleman's disease is a systemic lymphoproliferative disorder characterized by angiofollicular lymphoid proliferation causing fever, lymphadenopathy, hepatosplenomegaly, and rash. This uncommon, non-neoplastic disease is associated with an increased risk of Kaposi's sarcoma and lymphoid cancers. ${ }^{2}$ In addition, both Kaposi's sarcoma and multicentric Castleman's disease are characterized by vascular hyperplasia, dysregulation of the immune system, and increased plasma levels of interleukin-6., ${ }^{2,3}$ We recently cared for a patient who had HHV-8 infection associated with multicentric Castleman's disease and Kaposi's sarcoma.

In June 1999, a 54-year-old man began to notice lowgrade fever in the evening, lymph-node enlargement, and weakness. A lymph-node biopsy showed B follicles with Castleman-like features and proliferation of Kaposi's sarcoma in the same lymph node (Fig. 1A); other histological features of the lymph node are shown in Figure 1B, 1C, and 1D. The patient was negative for human immunodeficiency virus but strongly positive for KSHV antibody (titer, $1: 10,000)$, with a high level of KSHV viremia in mononuclear cells. He died two weeks later with hepatic coma.

Our findings underscore the association among KSHV, Kaposi's sarcoma, and multicentric Castleman's disease. The association of multicentric Castleman's disease with Kaposi's sarcoma and the finding of some features common to both diseases led us to search for $\mathrm{HHV}-8$ sequences in samples of multicentric Castleman's disease. In fact, HHV-8 DNA sequences have been demonstrated in a substantial percentage of cases of multicentric Castleman's disease. ${ }^{2}$ It is not known whether the KSHV-positive plasmablastic or immunoblastic cells in multicentric Castleman's disease are a feature of KSHV-negative multicentric Castleman's disease or whether the plasmablastic variant of this disease is specifically associated with KSHV., ${ }^{2,4}$ The importance of this case is related to the simultaneous presence of these two diseases in the same lymph node and the association with $\mathrm{KSHV}$ infection. This uncommon finding is another piece of evidence of the close link among KSHV, Kaposi's sarcoma, and multicentric Castleman's disease.

Antonino Mazzone, Mid. Elena OtTINi, M.D. Marco Paulli, M.D.

Istituto di Ricovero e Cura a Carattere Scientifico S. Matteo Hospital 27100 Pavia, Italy

1. Chang Y, Cesarman E, Pessin MS, et al. Identification of herpesviruslike DNA sequences in AIDS-associated Kaposi's sarcoma. Science 1994; 266:1865-9.

2. Parravicini C, Chandran B, Corbellino M, et al. Differential viral protein expression in Kaposi's sarcoma-associated herpesvirus-infected diseas- 

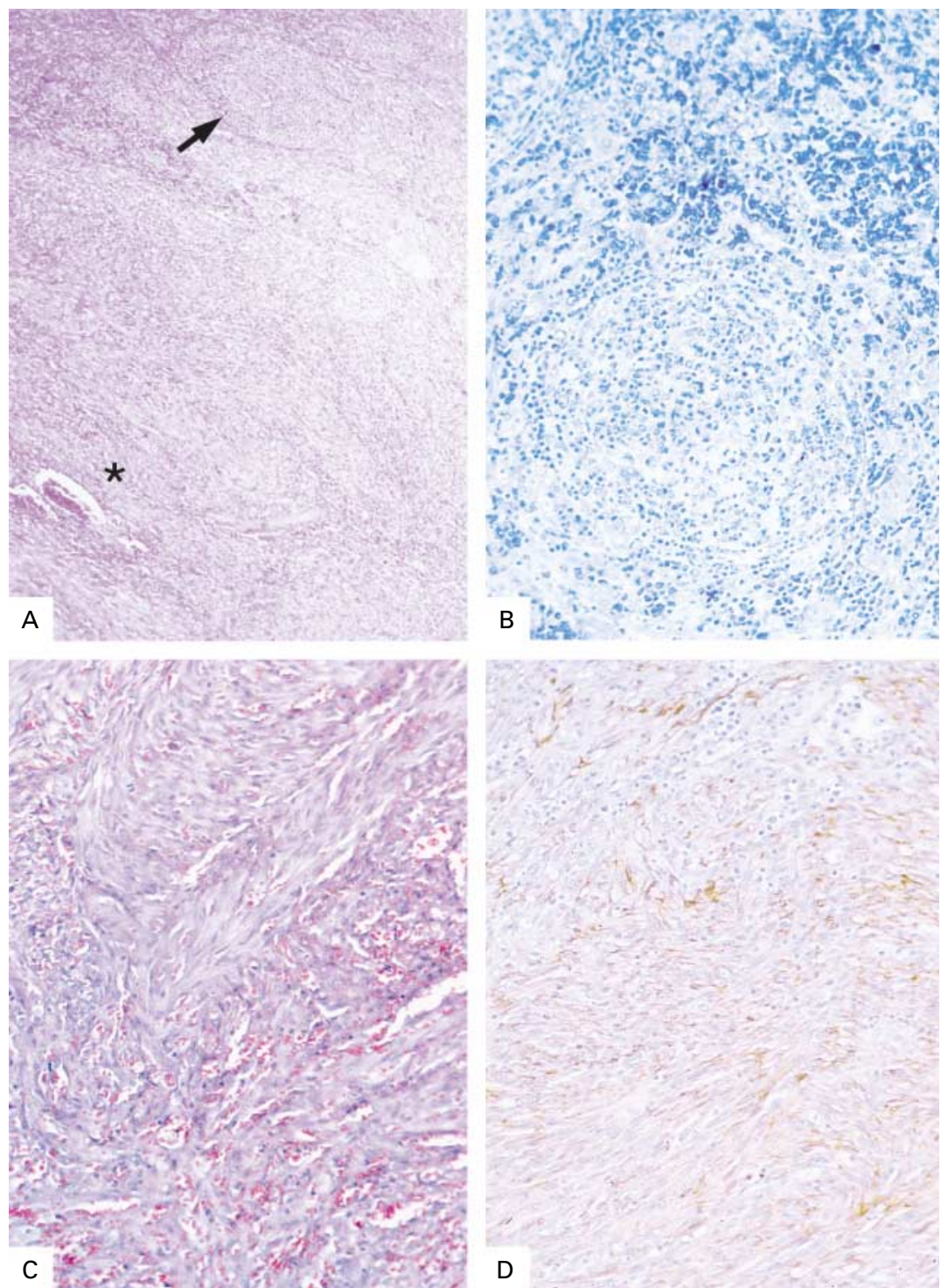

Figure 1. Findings in a Single Lymph Node.

Panel A shows B follicles with Castleman-like features (arrow) and proliferation of Kaposi's sarcoma (asterisk) (hematoxylin and eosin, $\times 10$ ). Panel B shows Castleman-like features: a B follicle with onionskin modifications, increased vascularization, and a reduction in the number of centrofollicular cells; pronounced plasmacytosis is evident in the follicular area (Giemsa, $\times 25$ ). Panel C shows Kaposi's sarcoma fusiform cells, arranged in fascicles, delineating slit-like vascular spaces containing erythrocytes (hematoxylin and eosin, $\times 25$ ). Panel D shows strong expression of factor VIII by the neoplastic cells of Kaposi's sarcoma (streptavidin-biotin-peroxidase method, $\times 25$ ).

es: Kaposi's sarcoma, primary effusion lymphoma, and multicentric Castleman's disease. Am J Pathol 2000;156:743-9.

3. Mazzucchelli I, Vezzoli M, Ottini E, Paulli M, Boveri E, Mazzone A A complex immunodeficiency: idiopathic CD4+ T-lymphocytopenia and hypogammaglobulinemia associated with HHV8 infection, Kaposi's sarcoma and gastric cancer. Haematologica 1999;84:378-80.

4. Belec L, Mohamed AS, Authier FJ, et al. Human herpesvirus 8 infection in patients with POEMS syndrome-associated multicentric Castleman's disease. Blood 1999;93:3643-53.
The authors reply:

To the Editor: Dr. Washenik and colleagues write that "treatment options for cases of less severe disease were omitted from the discussion" and that "until recently, the treatment of less severe cutaneous Kaposi's sarcoma has been limited to the destructive approaches of cryotherapy with liquid nitrogen and intralesional vinblastine." Actually, we 
extensively discussed treatments for patients with indolent or limited lesions, for which excisional surgical biopsy and even observation are totally appropriate. Radiation, particularly electron-beam radiation, was described in some detail, as were single-agent chemotherapy and oral etoposide. Retinoids (differentiating agents), including 9-cis-retinoic acid, were also described as having activity against Kaposi's sarcoma. Washenik and colleagues point out that 9-cis-retinoic acid in a gel form can also be effective in managing $\mathrm{cu}^{-}$ taneous AIDS-related Kaposi's sarcoma.

We certainly agree with Simonart and colleagues that human chorionic gonadotropin should be used with caution. Since we included the discussion of human chorionic gonadotropin in the section on experimental therapies, we clearly meant that the hormone should be used only in a clinical trial and not in clinical practice.

Kaposi's sarcoma was first described in 1872 by Moritz Kaposi, and Castleman's disease was described exactly one century later by Benjamin Castleman and colleagues. ${ }^{1}$ Since 1972, numerous patients with concurrent or sequential cases of Kaposi's sarcoma and Castleman's disease have been described, leading to speculation about a common or shared pathogenesis.

Along with other investigators, ${ }^{2-4}$ Mazzone and colleagues have clearly documented the simultaneous occurrence of Kaposi's sarcoma and Castleman's disease in the same lymph node. However, although both Kaposi's sarcoma and a subgroup of cases of Castleman's disease are caused by KSHV, the mechanisms underlying the development of these two lesions are likely to be very different. The virus in the two disorders demonstrates distinct, tissue-specific patterns of gene expression. ${ }^{5}$ One of the critical factors in the development of Castleman's disease is the abnormal expression of interleukin-6, whether of cellular or viral origin, whereas viral interleukin-6 is not expressed at all in Kaposi's sarcoma spindle cells.

Karen ANTMAN, M.D. YUAN CHANG, M.D. Columbia University College of Physicians and Surgeons New York, NY 10032

1. Keller AR, Hochholzer L, Castleman B. Hyaline-vascular and plasmacell types of giant lymph node hyperplasia of the mediastinum and other locations. Cancer 1972;29:670-83.

2. Xerri L, Guigou V, Lepidi H, Horschowski N, Lejeune C, Hassoun J. Lymphadenopathic tumor exhibiting intermingled features of Kaposi's sarcoma, malignant lymphoma, and angiofollicular hyperplasia. Arch Pathol Lab Med 1991;115:1162-6.

3. Gerald W, Kostianovsky M, Rosai J. Development of vascular neoplasia in Castleman's disease: report of seven cases. Am J Surg Pathol 1990;14: 603-14.

4. Rywlin AM, Rosen L, Cabello B. Coexistence of Castleman's disease and Kaposi's sarcoma: report of a case and a speculation. Am J Dermatopathol 1983;5:277-81

5. Parravicini C, Chandran B, Corbellino M, et al. Differential viral protein expression in Kaposi's sarcoma-associated herpesvirus-infected diseases: Kaposi's sarcoma, primary effusion lymphoma, and multicentric Castleman's disease. Am J Pathol 2000;156:743-9.

\section{Patients with Acute Chest Pain}

To the Editor: In their review article on the evaluation of patients with acute chest pain, Lee and Goldman (April 20 issue $)^{1}$ did not comment on the usefulness of measure- ments of serum myoglobin. Myoglobin, a relatively small protein $(17.8 \mathrm{kd})$, appears in the peripheral blood much earlier during acute myocardial infarction than other cardiac markers such as creatine kinase $\mathrm{MB}$ and troponins. The diagnostic sensitivity of myoglobin levels for acute myocardial infarction ranges from 43 to 100 percent. The wide variability is in large part due to differences in the cutoff values used to define a positive test (ranging from 50 to $150 \mu \mathrm{g}$ per liter) and in the timing of blood sampling. Because of the protein's early release and rapid clearance, the diagnostic accuracy of myoglobin levels is highly time dependent. In a prospective study involving 309 patients, de Winter et al. ${ }^{2}$ found that the optimal time to measure serum myoglobin was five hours after the onset of symptoms. With the use of a cutoff value of $50 \mu \mathrm{g}$ per liter, the serum myoglobin level has a sensitivity of 95 percent and a specificity of 86 percent for the diagnosis of acute myocardial infarction. The sensitivity can be increased to 98 percent (at the expense of a decrease in specificity, to 79 percent) if a cutoff value of $40 \mu \mathrm{g}$ per liter is chosen.

The usefulness of serum myoglobin levels as a marker for myocardial injury has been limited by its specificity, since elevated myoglobin levels are also found in patients with skeletal-muscle disorders and those with renal failure. However, excellent specificity can be achieved with serial measurements of myoglobin. Polanczyk et al. ${ }^{3}$ reported that the finding of a doubling of the myoglobin level over a period of two to three hours had a remarkably high specificity of 98 percent. Employing a different diagnostic threshold, Bushnell et al. ${ }^{4}$ found that a change in the rate of release of myoglobin of more than 20 ng per milliliter per hour had a specificity of 99 percent.

Thus, when applied appropriately, the myoglobin level can be a valuable adjunct in the evaluation of patients with chest pain. For example, the finding of a myoglobin level of less than $40 \mu \mathrm{g}$ per liter five hours after the onset of symptoms may give physicians in the emergency room the needed confidence to send patients with atypical chest pain home.

\section{WAQAS AHMED, M.D. T. Michael Fan, M.D., Ph.D. University of South Alabama Medical Center Mobile, AL 36617}

1. Lee $\mathrm{TH}$, Goldman L. Evaluation of the patient with acute chest pain. N Engl J Med 2000;342:1187-95.

2. de Winter RJ, Lijmer JG, Koster RW, Hoek FJ, Sanders GT. Diagnostic accuracy of myoglobin concentration for the early diagnosis of acute myocardial infarction. Ann Emerg Med 2000;35:113-20.

3. Polanczyk CA, Lee TH, Cook EF, Walls R, Wybenga D, Johnson PA. Value of additional two-hour myoglobin for the diagnosis of myocardial in farction in the emergency department. Am J Cardiol 1999;83:525-9.

4. Bushnell A, Woo J, Sunheimer R, McCabe JB. Utility of myoglobin in the evaluation of chest pain in the ED. Am J Emerg Med 1999;17:216-7.

To the Editor: It is surprising that a review of the evaluation of acute chest pain would fail to mention psychiatric causes. If cardiac ischemia seems unlikely to be the cause, Lee and Goldman recommend entertaining the possibility of pulmonary, gastrointestinal, musculoskeletal, and other cardiac conditions. Although they single out esophageal disease, they do not discuss the equally common roles of panic disorder and major depression in presentations involving acute chest pain. ${ }^{1}$ 
Numerous studies show that up to 30 percent of patients with chest pain have normal coronary angiograms. Katon and colleagues found that 38 percent of angiograms obtained in patients with chest pain and no previously documented heart disease were normal. More tellingly, 70 percent of the patients with normal angiograms met the criteria for panic disorder, major depression, or both, as compared with only 9 percent of the patients with abnormal angiograms. $^{2} \ldots$

John Michael Bostwick, M.D. Mayo Clinic Rochester, MN 55905

1. Cooke RA, Smeeton N, Chambers JB. Comparative study of chest pain characteristics in patients with normal and abnormal coronary angiograms. Heart 1997;78:142-6.

2. Katon W, Hall ML, Russo J, et al. Chest pain: relationship of psychiatric illness to coronary arteriographic results. Am J Med 1988;84:1-9.

The authors reply:

To the Editor: Not every topic can be fully explored in a brief review. We share Ahmed and Fan's interest in myoglobin, and our group has studied this topic. ${ }^{1}$ Nevertheless, the measurement of myoglobin has not been used routinely in patients with acute chest pain because of its poor specificity and because indexes based on changes in serial myoglobin values do not give clinicians the qualitative guidance (yes vs. no) that they find most useful.

We agree with Dr. Bostwick that panic disorder and depression are common causes of chest discomfort and should be considered in the comprehensive evaluation of patients with typical or atypical chest pain, especially when other causes are not evident. In the acute care setting, however, the primary focus must be on conditions that are potentially life-threatening in the short term.

Thomas H. LeE, M.D.

Partners Community HealthCare Boston, MA 02199-8001

Lee Goldman, M.D. University of California, San Francisco San Francisco, CA 94143-0120

1. Polanczyk CA, Lee TH, Cook EF, Walls R, Wybenga D, Johnson PA. Value of additional two-hour myoglobin for the diagnosis of myocardial in farction in the emergency department. Am J Cardiol 1999;83:525-9.

\section{Blindness in a Vegan}

To the Editor: Enthusiasm is laudable, but simplicity is even better.

The reports by Li and McKay and by Milea et al. (March 23 issue $)^{1,2}$ surprised me because of the excessive diagnostic testing used in patients who were anemic and nutritionally deficient as a result of strict, unsupplemented vegan diets. The dietary histories of the two patients should have been sufficient for understanding the etiology and pathogenesis of their conditions and for determining their treatment. I am puzzled by the need for small-bowel x-ray studies, endos- copy and multiple gastric biopsies, and mitochondrial-DNA analysis at the start.

\author{
Harvey E. Finkel, M.D. \\ 92 Dean Rd. \\ Brookline, MA 02445-4244
}

1. Li K, McKay G. Ischemic retinopathy caused by severe megaloblastic anemia. N Engl J Med 2000;342:860.

2. Milea D, Cassoux N, LeHoang P. Blindness in a strict vegan. N Engl J Med 2000;342:897-8.

To the Editor: The two reports of nutritional deficiency in vegans include a case of anemia-associated retinopathy, in which the fundus photographs were rotated 90 degrees from their proper orientation, and a case of optic neuropathy and peripheral neuropathy. The authors of the latter report make the undocumented assertion that vegetarians are at risk for nutritional deficiency if they do not receive vitamin supplementation. Although I agree that vegans should include a source of vitamin $B_{12}$ in their diet, there is no evidence that supplementation of other nutrients is necessary or even desirable in those following a balanced diet.

Remarkably, both of the patients described in these reports were deficient in folate, despite the fact that numerous studies have found that both vegan and nonvegan vegetarians tend to have higher intakes of folate and higher plasma levels of folate than do omnivores. ${ }^{1-3}$ These findings are not surprising, considering that leafy green vegetables, legumes, and several fruits are among the richest sources of folate. The patient described by Milea et al. was also said to be deficient in vitamins $\mathrm{C}$ and $\mathrm{E}$, both of which are derived primarily from plant sources.

Clearly, then, these patients were not usual vegans but rather persons who were following anomalous vegan practices. To impute the tendency toward nutritional deficiency in such persons to the majority of vegans, who follow normative dietary practices, is inappropriate and, unfortunately, all too common in the medical literature. Vegetarian diets rich in a variety of fruits and vegetables represent the ideal from a disease-prevention standpoint, undoubtedly because they provide the phytochemicals that are so lacking in the average Western diet.

Jay B. Lavine, M.D.

P.O. Box 43126

Tucson, AZ 85733-3126

1. Haddah EH, Berk LS, Kettering JD, Hubbard RW, Peters WR. Dietary intake and biochemical, hematologic, and immune status of vegans compared with nonvegetarians. Am J Clin Nutr 1999;70:Suppl:586S-593S. 2. Harman SK, Parnell WR. The nutritional health of New Zealand vegetarian and non-vegetarian Seventh-day Adventists: selected vitamin, mineral and lipid levels. N Z Med J 1998;111:91-4.

3. Fenech M, Rinaldi J. A comparison of lymphocyte micronuclei and plasma micronutrients in vegetarians and non-vegetarians. Carcinogenesis 1995; 16:223-30.

The authors reply:

To the Editor: We agree with Finkel that the dietary history helped us to determine the right diagnosis in our patient, but diagnostic testing was necessary to rule out other possible causes of his condition, such as compression or 
mitochondrial disease. It is important to exclude other causes of optic neuropathy before accepting a nutritional origin. ${ }^{1}$

Our patient, being an "unusual" vegan, as Lavine suggests, had not only an unsupplemented but also an inappropriately strict vegan diet. He had no nutritional counseling and retrospectively admitted excessive restriction of his diet, although he did not seem to be anorexic or mentally ill. Several nutritional deficiencies have been reported in vegans, ${ }^{2,3}$ but the unexpected low levels of folate and vitamins $\mathrm{C}$ and $\mathrm{E}$ in our patient may have been caused by inadequate nutrition, probably due to a diet that was not in accordance with recommended vegan practices. Therefore, appropriate guidance and nutritional supplementation could have been useful in this particular case.

\section{Dan Milea, M.D. \\ Nathalie Cassoux, M.D. Phuc LeHoang, M.D., Ph.D. \\ Groupe Hospitalier Pitié-Salpêtrière 75651 Paris CEDEX 13, France}

1. Miller NR, Newman NJ. The essentials: Walsh \& Hoyt's clinical neuroophthalmology. 5th ed. Baltimore: Williams \& Wilkins, 1999:664.

2. Zmora E, Gorodischer R, Bar-Ziv J. Multiple nutritional deficiencies in infants from a strict vegetarian community. Am J Dis Child 1979;133:141-

3. Remer T, Neubert A, Manz F. Increased risk of iodine deficiency with vegetarian nutrition. Br J Nutr 1999;81:45-9.

\section{Invasive Pulmonary Aspergillosis Associated with High-Dose Inhaled Fluticasone}

To the Editor: A 44-year-old man with moderately severe asthma was first seen in the infectious-disease clinic in November 1999 because of a recent diagnosis of pulmonary aspergillosis. The patient had noted an increase in his asthma symptoms during the summer of 1999 . A chest $x$-ray film obtained at that time had revealed bilateral cavitary lesions. An open-lung biopsy in September 1999 had revealed chronic necrotizing aspergillosis.

The patient had no known history of immunosuppression. His medications included fluticasone (delivered in two puffs of $220 \mu \mathrm{g}$ four times a day [total daily dose, $1760 \mu \mathrm{g}$ ]) and zafirlukast (20 mg per day). The patient was initially treated with oral itraconazole for invasive pulmonary aspergillosis. Repeated imaging showed progression of disease. Hemoptysis developed. Treatment was switched to an investigational antifungal medication. During the course of therapy, hypertension developed and the patient's abdominal girth increased. The results of a cosyntropin (Cortrosyn) stimulation test were consistent with the presence of adrenal insufficiency. The dose of inhaled corticosteroids was gradually tapered. Recent computed tomographic scans of the thorax demonstrate improvement, the patient's cough has decreased, and he has had no further episodes of hemoptysis.

High-dose systemic corticosteroids are a risk factor for invasive aspergillosis. We believe that this is the first reported case of invasive pulmonary aspergillosis associated with an inhaled corticosteroid. A Medline search produced one reported case of laryngeal aspergillosis associated with inhaled fluticasone. ${ }^{1}$

Fluticasone is the most potent inhaled corticosteroid available in the United States. It was made available because it has greater topical potency, a higher degree of retention in tissue, and a longer half-life than the other inhaled corticosteroids. Inhaled corticosteroids have been linked to adverse effects traditionally associated with systemic corticosteroids, including adrenal suppression and effects on linear growth and bone metabolism. ${ }^{2}$ There have been numerous reports of adrenal insufficiency associated with the use of inhaled corticosteroids. A meta-analysis of studies of adrenal suppression among patients who used inhaled corticosteroids demonstrated that fluticasone was nearly twice as likely to cause adrenal suppression as beclomethasone, triamcinolone, or budesonide at equivalent dosages. The effects were more obvious at daily doses of more than $0.8 \mathrm{mg} .^{3}$

Our findings add to a growing body of evidence that in certain patients, inhaled corticosteroids can exert clinically significant systemic effects. Patients who are taking high doses may be at risk for secondary immunosuppression and opportunistic infection. Practitioners should be aware of these risks when they prescribe these medications, particularly the more potent formulations.

\section{Brett A. Leav, M.D. Barry Fanburg, M.D. Susan Hadley, M.D. New England Medical Center Boston, MA 02111}

1. Fairfax AJ, David V, Douce G. Laryngeal aspergillosis following high dose inhaled fluticasone therapy for asthma. Thorax 1999;54:860-1. 2. Wilson AM, Blumsohn A, Jung RT, Lipworth BJ. Asthma and Cushing's syndrome. Chest 2000;117:593-4

3. Lipworth BJ. Systemic adverse effects of inhaled corticosteroid therapy: a systematic review and meta-analysis. Arch Intern Med 1999;159:941-55.

(C)2000, Massachusetts Medical Society. 